\title{
Carbon Nanotube-Supported Copper-Cobalt Catalyst for the Production of Higher Carbon Number Alcohols through Carbon Monoxide Hydrogenation
}

\author{
Peng Wang, ${ }^{a}$ Xihua Du, ${ }^{*, a}$ Wenchang Zhuang, ${ }^{a}$ Keying Cai, ${ }^{a}$ Jing Li, ${ }^{a}$ Yan Xu, ${ }^{a}$ \\ Yingmei Zhou, ${ }^{a}$ Kai Sun, ${ }^{b}$ Shuyao Chen, ${ }^{b}$ Xiaoli Li ${ }^{b}$ and Yisheng Tan ${ }^{*, b}$ \\ ${ }^{a}$ School of Chemistry and Chemical Engineering, Xuzhou Institute of Technology, \\ 221018 Xuzhou, China \\ ${ }^{b}$ State Key Laboratory of Coal Conversion, Institute of Coal Chemistry, \\ Chinese Academy of Sciences, 030001 Taiyuan, China
}

\begin{abstract}
A series of carbon nanotube (CNTs)-supported copper-cobalt catalysts were prepared and investigated in a slurry reactor for their ability to selectively convert syngas into higher carbon number alcohols. The 7.5Cu7.5Co/CNTs catalyst achieved superior selectivity towards the formation of ethanol (30.1\%) and $\mathrm{C}_{2+}$ alcohols $(57.7 \%)$, while the $10 \mathrm{Co} 5 \mathrm{Cu} / \mathrm{CNTs}$ catalyst exhibited the largest alcohol space-time yield $\left(372.9 \mathrm{mg} \mathrm{g}_{\mathrm{cat}}{ }^{-1} \mathrm{~h}^{-1}\right)$. However, the pure $\mathrm{Cu}(15 \mathrm{Cu} / \mathrm{CNTs})$ catalyst displayed negligible activity. Cobalt reduction was enhanced in the presence of copper. In addition to the $\mathrm{Cu}^{0}-\mathrm{Co}^{0}$ center, $\mathrm{Co}^{0}-\mathrm{Co}^{2+}$ also presented dual active sites for higher alcohols synthesis, the $\mathrm{Co}^{2+}$ site could terminate carbon chain growth to produce alcohols. The ratio of $\mathrm{Cu} / \mathrm{Co}$ considerably influences the metal particle properties-synergistically effecting the active species.
\end{abstract}

Keywords: CO hydrogenation, higher alcohols synthesis, CuCo, carbon nanotube

\section{Introduction}

The conversion of synthesis gas derived from coal, natural gas or biomass into higher carbon number alcohols is both attractive and challenging to the field of $\mathrm{C} 1$ chemistry. ${ }^{1-3}$ The alcohols obtained from this process can be used as fuel blends or as value-added chemicals in fine chemical synthesis. ${ }^{4,5}$ Furthermore, higher alcohols synthesis (HAS) is a prototypical example of reactions that rely on synergistic effects between dual catalytic sites with different functionalities, one active site catalysis $\mathrm{CO}$ dissociation, while the second site enables $\mathrm{CO}$ non-dissociation centers to form. ${ }^{6}$ Typically, among the available non-precious metal catalysts, modified bimetallic Fischer-Tropsch (FT) catalysts (e.g., CuCo) are widely investigated as one of the most promising candidates for HAS. ${ }^{7,8}$

Therefore, synergistic combination of two metals represents an efficient approach towards desirable catalytic properties by the creation of hybrid sites, and intimate contact between the metal components has been recognized as important to achieve satisfactory selectivity. It is

*e-mail: 12dxh@sina.com; tan@sxicc.ac.cn known that Co species are the center for $\mathrm{CO}$ dissociation, hydrogenation and chain propagation to form surface alkyl species, while $\mathrm{Cu}$ species are the site for molecularly absorbed CO insertion and alcohol formation..$^{910}$ The synergistic effect and the surface distribution of the two active components have significant influence on the catalytic performance for the synthesis of alcohols. ${ }^{11,12}$ It has been demonstrated that the porous structure of the support may efficiently control metal dispersion. ${ }^{13,14}$ For supported catalysts, metal particle size is typically limited by the pore size of the support and the support texture may prevent sintering of the metal particles ${ }^{15}$ or limit sintering to the maximum pore diameter. ${ }^{16,17}$ Furthermore, it is expected that the nature of the support may influence copper-cobalt interactions, which may lead to different active phase structures and properties. $\mathrm{SiO}_{2}, \mathrm{Al}_{2} \mathrm{O}_{3}$ and $\mathrm{TiO}_{2}$ have different interactions with cobalt species. Strongly interacting supports such as $\gamma-\mathrm{Al}_{2} \mathrm{O}_{3}$ usually lead to high cobalt oxide dispersions, however, there is difficulty to reduce cobalt species. ${ }^{18}$ To obtain appropriate $\mathrm{Cu}$ and $\mathrm{Co}$ nanoparticle properties and distribution in the catalyst, carbon nanotubes (CNTs) are employed as supports. A wealth of interdependent research ${ }^{19-21}$ has demonstrated the advantages of using CNTs as supports 
to improve transition metal particle dispersion in catalysts and the confinement effects during catalysis have been systematically studied. Previous studies concluded that space restriction, ${ }^{22}$ enrichment of reactants inside $\mathrm{CNTs}^{23}$ and the electronic interaction of the confined materials within $\mathrm{CNTs}^{24}$ is expected to facilitate cobaltous oxide reduction. Therefore, there is a need to minimize the distance between dual catalytic sites, while maintaining active particles of sufficiently small size with a high degree of dispersion induced by the confinement effects of nanotubes.

In the present study, a series of CNTs-supported $\mathrm{CuCo}$-based precursors with different $\mathrm{Cu} / \mathrm{Co}$ ratios were synthesized using a simple and effective co-impregnation method. After calcination, a homogeneous and highly dispersed bimetallic catalyst was obtained, as revealed by high-resolution transmission electron microscopy (HRTEM) analysis. In situ X-ray photoelectron spectroscopy (XPS) indicated $\mathrm{Cu}^{0}-\mathrm{Co}^{0}$ and $\mathrm{Co}^{0}-\mathrm{Co}^{2+}$ centers were the active sites for HAS in our system. The catalytic performance of the catalysts prepared in this work towards the hydrogenation of carbon monoxide was examined in a slurry reactor. The maximum space-time yield (STY) reached $372.9 \mathrm{mg} \mathrm{gat}^{-1} \mathrm{~h}^{-1}$ and an ethanol selectivity as high as $30.1 \%$ was obtained. Improved synergistic effects were observed between the dual active sites at a $\mathrm{Cu} / \mathrm{Co}$ ratio range of 0.5-2, with the ratio exerting significant influence on the catalytic performance.

\section{Experimental}

\section{Materials}

Analytical-grade chemicals, including $\mathrm{Cu}\left(\mathrm{NO}_{3}\right)_{2} \cdot 3 \mathrm{H}_{2} \mathrm{O}$ and $\mathrm{Co}\left(\mathrm{NO}_{3}\right)_{2} \cdot 6 \mathrm{H}_{2} \mathrm{O}$ were purchased from the Beijing Chemical Co., Ltd. and were used as received without further purification. Multi-walled CNTs (outer diameter $<8 \mathrm{~nm}$, lengths $10-30 \mu \mathrm{m}$ ) were purchased from Chengdu Organic Chemicals. High-resolution transmission electron microscope (HRTEM) analysis showed that the average inner diameter of CNTs was around $3.9 \mathrm{~nm}$ and the wall thickness of it was in the range of 1.5-3 nm. Raw CNTs were refluxed in $\mathrm{HNO}_{3}$ (68 wt.\%) for $14 \mathrm{~h}$ at $140{ }^{\circ} \mathrm{C}$ in an oil bath to purify and cut the carbon tubes, in contrast, CNTs with closed caps were obtained by refluxing CNTs in $37 \mathrm{wt} . \% \mathrm{HNO}_{3}$ for $5 \mathrm{~h}$ at $100^{\circ} \mathrm{C}$. Then, the mixture was filtered and washed with deionized water, followed by drying at $60^{\circ} \mathrm{C}$ for $12 \mathrm{~h}$. HRTEM analysis indicated that the ends of the CNTs were open and the lengths of them were $0.5-2 \mu \mathrm{m}$.

\section{Synthesis of $\mathrm{Cu} / \mathrm{Co}$-based catalysts}

The CNTs were immersed in an ethanolic solution of precursor salts of $\mathrm{Cu}, \mathrm{Co}$ and then subjected to ultrasonic treatment and stirring. The ultrasonic treatment and stirring facilitated the filling of the CNT channels with the precursor solution during impregnation. After $10 \mathrm{~h}$ of impregnation, the mixture was dried at $60{ }^{\circ} \mathrm{C}$ overnight, followed by heating to $110{ }^{\circ} \mathrm{C}$ for $10 \mathrm{~h}$. This process afforded a homogeneous distribution of the active components inside the channels of the CNTs. After drying, the products were calcined in $\mathrm{N}_{2}$ at $673 \mathrm{~K}$ for $4 \mathrm{~h}$ with a heating rate of $2 \mathrm{~K} \mathrm{~min}^{-1}$. A series of catalysts were prepared using this method, i.e., $15 \mathrm{Co} / \mathrm{CNTs}, 12.5 \mathrm{Co} 2.5 \mathrm{Cu} / \mathrm{CNTs}$, $10 \mathrm{Co} 5 \mathrm{Cu} / \mathrm{CNTs}, 7.5 \mathrm{Cu} 7.5 \mathrm{Co} / \mathrm{CNTs}, 10 \mathrm{Cu} 5 \mathrm{Co} / \mathrm{CNTs}$, $12.5 \mathrm{Cu} 2.5 \mathrm{Co} / \mathrm{CNTs}, 15 \mathrm{Cu} / \mathrm{CNTs}$, and the active components supported on CNTs with closed caps was denoted as $10 \mathrm{Cu} 5 \mathrm{Co}$-out-CNTs. These numbers stand for the loading metals weight contents.

\section{Characterization}

Powder X-ray diffraction patterns (XRD) were recorded over the $2 \theta$ range from 5 to $85^{\circ}$ using a Rigaku MiniFlex II $\mathrm{X}$-ray diffractometer, which was operated at $40 \mathrm{kV}$ and $40 \mathrm{~mA}$ with $\mathrm{Cu} \mathrm{K} \alpha$ radiation $(\mathrm{k}=0.15418 \mathrm{~nm})$.

$\mathrm{H}_{2}$-temperature-programmed reduction mass spectrometry analysis $\left(\mathrm{H}_{2}\right.$-TPR-MS) was performed to investigate the reducibility of the catalysts using a chemisorption instrument (TP-5080) and the sweep gas was detected using an OmniStar instrument. The catalyst $(50 \mathrm{mg})$ was pre-treated at $300{ }^{\circ} \mathrm{C}$ under a flow of $\mathrm{N}_{2}\left(32 \mathrm{~mL} \mathrm{~min}^{-1}\right)$ for $1 \mathrm{~h}$ and then cooled to $50{ }^{\circ} \mathrm{C}$; after cooling, the flow was changed to a $\mathrm{H}_{2} / \mathrm{N}_{2}=0.09$ mixture $\left(35 \mathrm{~mL} \mathrm{~min}^{-1}\right)$. The temperature-programmed reduction was performed between 50 and $800{ }^{\circ} \mathrm{C}$ with a heating rate of $10{ }^{\circ} \mathrm{C} \mathrm{min}^{-1}$.

$\mathrm{X}$-ray photoelectron spectroscopy (XPS) and X-ray Auger electron spectroscopy (XAES) were used to analyze the change in the surface composition using an AXIS ULTRA DLD instrument equipped with Al K $\alpha$ $(\mathrm{h} v=1486.6 \mathrm{eV})$. The sample was reduced in situ under a flow of $\mathrm{H}_{2}$ at $400{ }^{\circ} \mathrm{C}$ for $1 \mathrm{~h}$, and the following photoelectron lines were recorded: $\mathrm{Cu} 2 \mathrm{p}, \mathrm{Co} 2 \mathrm{p}, \mathrm{C} 1 \mathrm{~s}$ and $\mathrm{O} 1 \mathrm{~s}$. The binding energy values were corrected for charging effects by referring to the adventitious $\mathrm{C} 1 \mathrm{~s}$ line at $284.5 \mathrm{eV}$.

The chemical compositions ( $\mathrm{Cu}$ and $\mathrm{Co}$ ) of the as-prepared samples were determined by inductively coupled plasma-atomic emission spectroscopy (ICP-AES) using a Thermo iCAP 6300 instrument.

The textural properties of catalysts were measured by using the $\mathrm{N}_{2}$-sorption isotherm at $77 \mathrm{~K}$ on a Micromeritics 
ASAP2020 analyzer. Prior to each measurement, the sample was degassed at $200{ }^{\circ} \mathrm{C}$ overnight. The specific surface area was calculated by using the Brunauer-EmmettTeller (BET) equation. The micropore volume was obtained from the t-plot method. The mesopore volume was obtained from the Barrett-Joyner-Halenda (BJH) method using the desorption branch. The pore size distributions were evaluated by using the density functional theory (DFT) method applied to the nitrogen adsorption data.

The morphologies and microstructures of the materials were observed using a high-resolution transmission electron microscope (JEOL, JEM-2100F), which was operated at $200 \mathrm{kV}$, with a lattice resolution of $0.14 \mathrm{~nm}$.

\section{Catalysis studies}

Carbon monoxide hydrogenation reactions were performed in a $0.5 \mathrm{~L}$ continuous slurry reactor equipped with a mechanical agitator. The reactions were conducted at a temperature of $573 \mathrm{~K}$ and pressure of $4.5 \mathrm{MPa}$, using a feed gas of a 2:1 mixture of $\mathrm{H}_{2}$ and $\mathrm{CO}$ at a space velocity of $10000 \mathrm{~mL} \mathrm{~g}_{\text {cat }}{ }^{-1} \mathrm{~h}^{-1}$. The catalysts were reduced with a $10 \%$ hydrogen-in-nitrogen mixture for $3 \mathrm{~h}$ at $673 \mathrm{~K}$ in a tube furnace. After cooling to room temperature under a flow of high purity nitrogen, the reduced catalysts were added into an agate mortar with liquid paraffin, the solid particles were finely powdered, then the mixed liquid paraffin were transferred into the slurry reactor. All experimental data were obtained under steady-state conditions that were invariably maintained for $7 \mathrm{~h}$ and no deactivation was observed. The products were analyzed using five online gas chromatographs (GCs) during the reaction. The organic gas products, consisting of hydrocarbons and methanol, were detected online by flame ionization measurements using a GC4000A (GDX-403 column). The long chain hydrocarbons in the oil phase were detected by flame ionization measurements using a GC-2010 (Rtx-1 capillary column). The inorganic gas products were detected online by thermal conductivity measurements using a GC4000A (carbon molecular sieves column). The $\mathrm{H}_{2} \mathrm{O}$ and methanol products in the liquid phase were detected by thermal conductivity measurements using a GC4000A (GDX-401 column). The alcohol products in the liquid phase were detected by flame ionization measurements using a GC-7AG (Chromosorb 101).

\section{Results and Discussion}

Structural and morphological study of the catalysts

Figure 1 presents the XRD patterns of the fresh catalyst samples. As shown, the characteristic CNTs peak was observed at a $2 \theta$ value of $25.8^{\circ}$ and the intensity of peaks decreased gradually as a function of increased cobalt loading. The $15 \mathrm{Cu} / \mathrm{CNTs}$ catalyst primarily consisted of a $\mathrm{Cu}_{2} \mathrm{O}$ phase, with corresponding $2 \theta$ peak reflections positioned at $36.5,42.4,61.5,73.7$ and $77.6^{\circ}$ (JCPDS No. 65-3288). Additionally, the $\mathrm{CuO}$ phase was also present in both the $15 \mathrm{Cu} / \mathrm{CNTs}$ and $12.5 \mathrm{Cu} 2.5 \mathrm{Co} / \mathrm{CNTs}$ samples. As observed, the diffraction peak intensity of the $\mathrm{CuO}$ and $\mathrm{Cu}_{2} \mathrm{O}$ species decreased gradually as the loading of $\mathrm{Cu}$ decreased. Furthermore, when the $\mathrm{Co}$ loading exceeded that of $\mathrm{Cu}$, peaks corresponding to $\mathrm{CoO}$ (JCPDS No. 65-5474) were observed at very low intensities in these samples. In addition, carbon nanotubes seem to stabilize the $\mathrm{CoO}$ phase, which is usually unstable under ambient conditions. No other XRD characteristic peaks and significant shift of peaks were observed in these patterns, as bulk $\mathrm{CoCu}$ alloy may not be formed in the catalysts, due to the low solubility between $\mathrm{Co}$ and $\mathrm{Cu}$. Furthermore, $\mathrm{CuCo}_{2} \mathrm{O}_{4}$ spinel or $\mathrm{Cu}^{2+}{ }_{x} \mathrm{Co}^{2+}{ }_{1-\mathrm{x}} \mathrm{Co}^{3+}{ }_{2} \mathrm{O}_{4}$ structure may also not exist in these samples because of the absence of $\mathrm{Co}_{3} \mathrm{O}_{4}$ phase. ${ }^{25}$

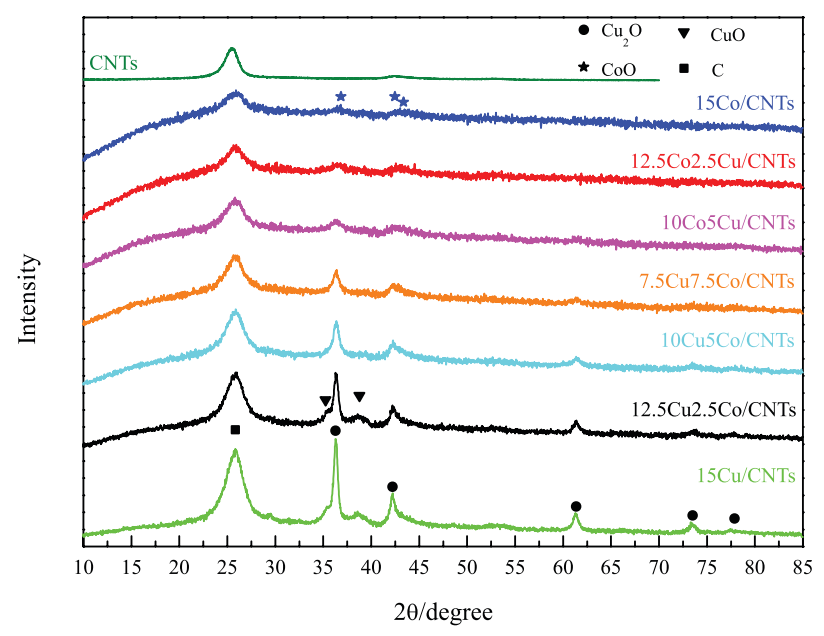

Figure 1. XRD patterns of the fresh catalysts.

The HRTEM images (Figures 2a-c) show nanoscale rows of metal particles in close proximity to each. As observed, the distances between two adjacent planes, d, were measured to be 0.24 and $0.21 \mathrm{~nm}$, which are characteristic of $\mathrm{Cu}_{2} \mathrm{O}$ and $\mathrm{CoO}$ phases, respectively. It is expected that such intimate contact among the metal particles would greatly improve the synergism of the $\mathrm{Cu}-\mathrm{Co}$ dual sites and reduce side reactions. More HRTEM images are shown in Supplementary Information section (Figure S2), which could analyze the distribution of metal particles clearly. Additionally, approximately $81 \%$ of the particles reside within the channels of the $10 \mathrm{Co} 5 \mathrm{Cu} / \mathrm{CNTs}$. In contrast, as shown in Figure 2e, 100\% of the particles were located on 
the exterior surface of 10Cu5Co-out-CNTs. Furthermore, the particle size distribution of the $10 \mathrm{Co} 5 \mathrm{Cu} / \mathrm{CNTs}$ catalyst (Figure 2c), shows a size distribution of 2-4 nm both inside and outside the nanotubes. However, the main particles size increased to $10-20 \mathrm{~nm}$ for $10 \mathrm{Cu} 5 \mathrm{Co}-$ out-CNTs. After reaction, as shown in Figures 2d-f, grain growth of nanoparticles were found in the samples. The most abundant particles were in the size range of $2-30 \mathrm{~nm}$ for $10 \mathrm{Co} 5 \mathrm{Cu} / \mathrm{CNTs}$ and $10-40 \mathrm{~nm}$ for $10 \mathrm{Cu} 5 \mathrm{Co}$-out-CNTs. It is also observed that many particles still encapsulated within the channels of $10 \mathrm{Co} 5 \mathrm{Cu} / \mathrm{CNTs}$ after reaction. Therefore, the confinement effect of carbon nanotubes may considerably influence the distribution of metal particles, without the confinement effect of the tubes, the cobalt and copper particles are easily aggregated during the reaction.
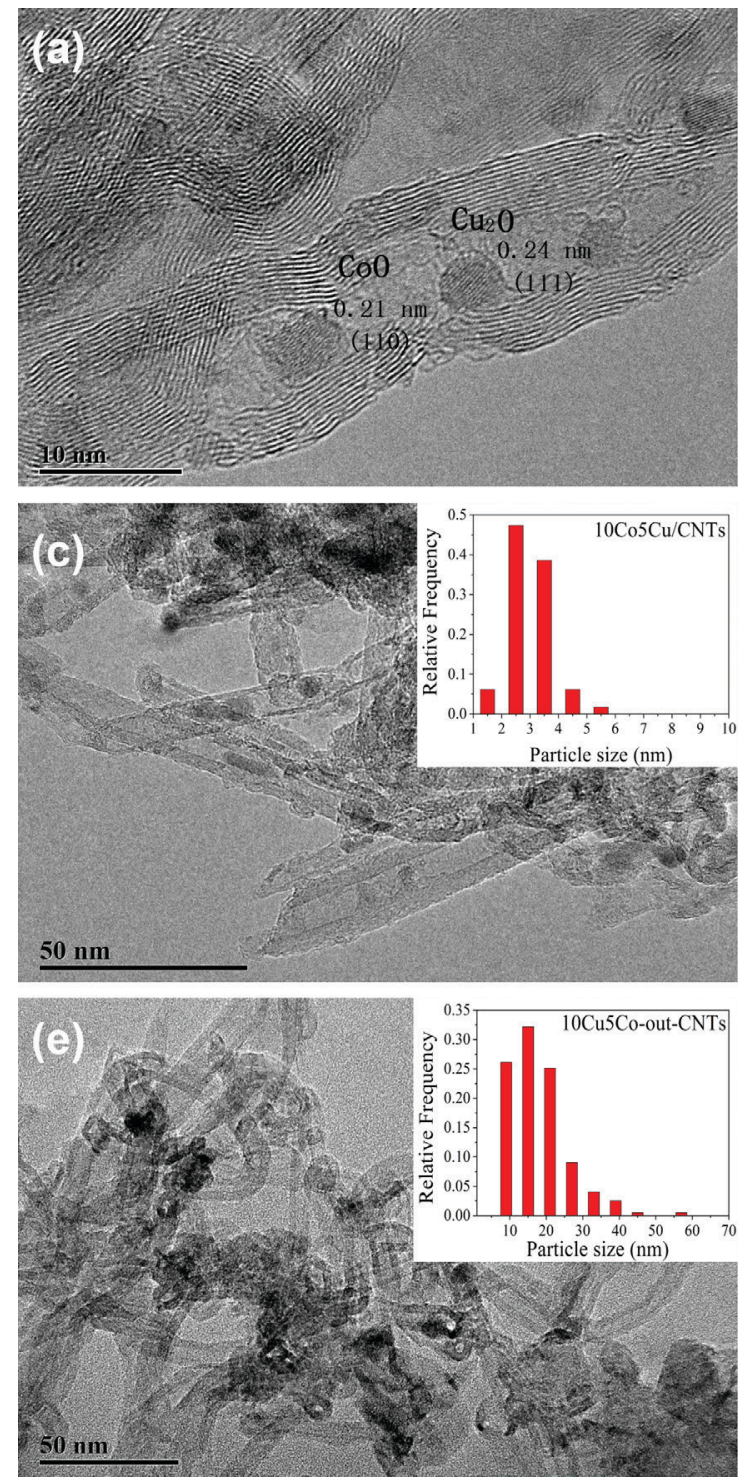

The $\mathrm{N}_{2}$-physisorption isotherms of the $10 \mathrm{Co} 5 \mathrm{Cu} / \mathrm{CNTs}$ catalyst are shown in Figure 3. According to the IUPAC classification, the catalyst exhibits a type IV isotherm having an inflection point around $\mathrm{P} / \mathrm{P}_{0}=0.4$. The $\mathrm{BJH}$ model was used to estimate mesopore size distributions. As shown in Figures 3a-b, it is observed that these samples possessed two types of mesopores, the CNT channels present a narrow pore size distribution with a pronounced peak at $3.4 \mathrm{~nm}$, while the less uniform mesopores in the range of $10-50 \mathrm{~nm}$ were assigned to the interstitial voids among the CNTs. The BET surface area of the $10 \mathrm{Co} 5 \mathrm{Ce} / \mathrm{CNT}$ and CNTs samples were 226 and $248 \mathrm{~m}^{2} \mathrm{~g}^{-1}$, respectively. It is indicated that all the samples has the similar BET surface area and pore size distribution.
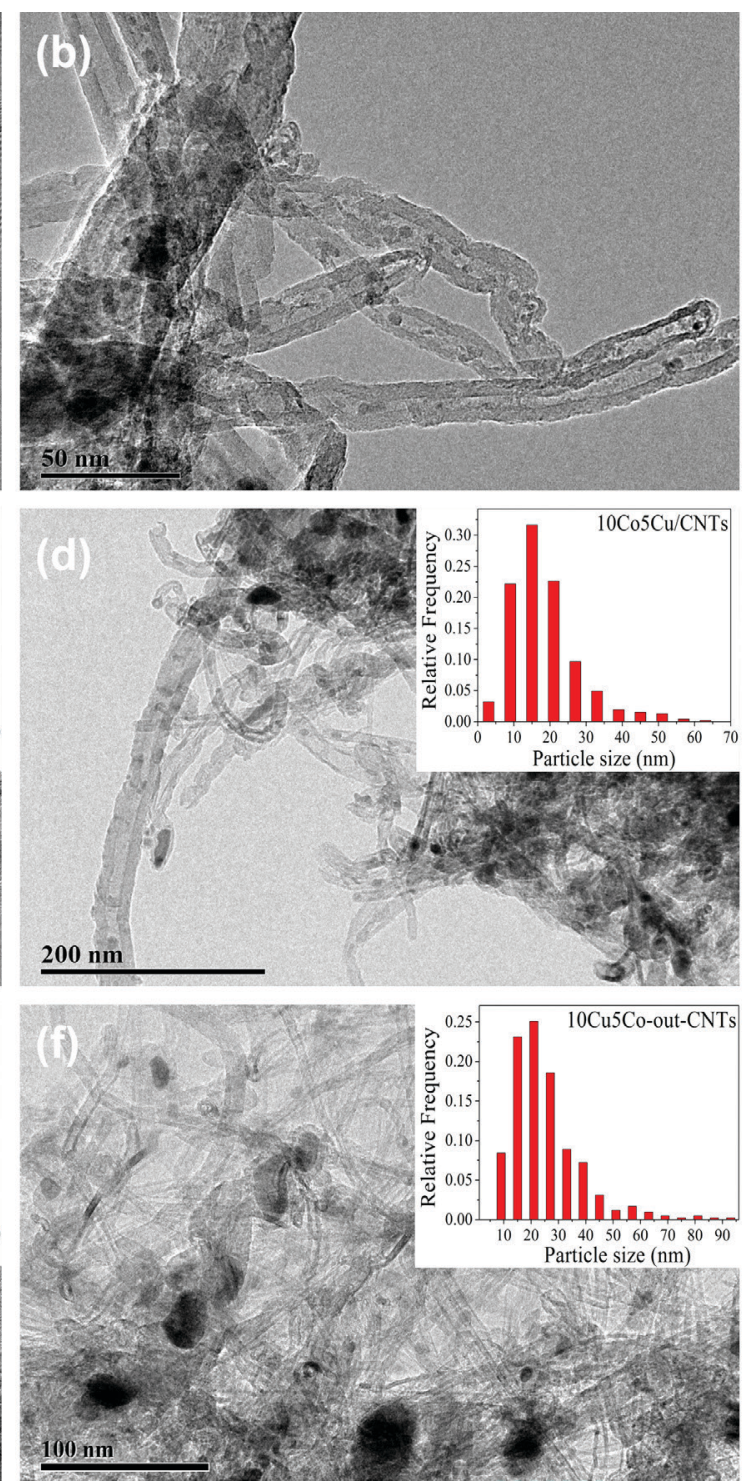

Figure 2. HRTEM images of fresh (a) $10 \mathrm{Cu} 5 \mathrm{Co} / \mathrm{CNTs}$; (b) $7.5 \mathrm{Cu} 7.5 \mathrm{Co} / \mathrm{CNTs}$; (c) $10 \mathrm{Co} 5 \mathrm{Cu} / \mathrm{CNTs}$ catalyst; (e) $10 \mathrm{Cu} 5 \mathrm{Co}-$ out-CNTs; HRTEM images of used (d) $10 \mathrm{Co} 5 \mathrm{Cu} / \mathrm{CNTs}$; (f) $10 \mathrm{Cu} 5 \mathrm{Co}$-out-CNTs, (600-700 particles were counted to determine the particle size distribution, and 300-400 particles were counted to calculate the percentage of particles inside and outside of the tubes). 

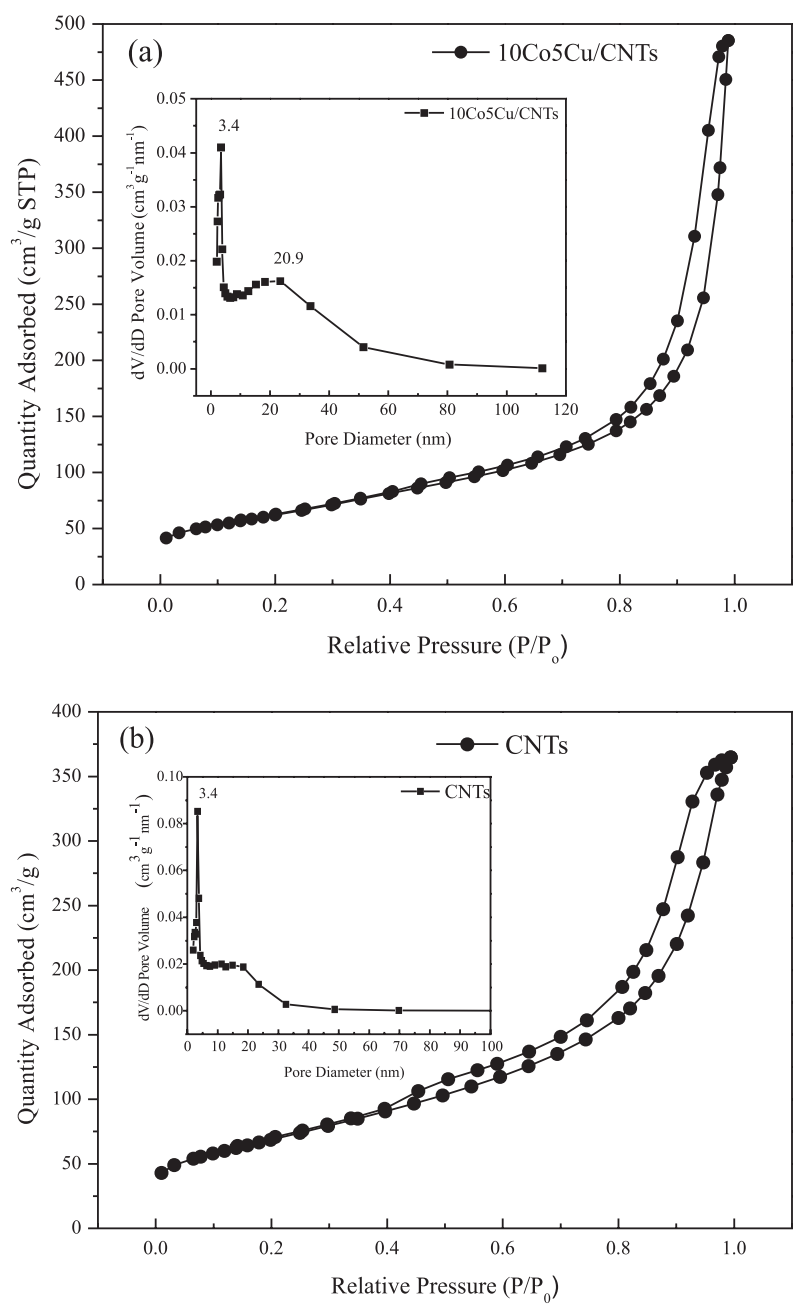

Figure 3. Nitrogen adsorption-desorption isotherms and pore size distributions of (a) the fresh $10 \mathrm{Co} 5 \mathrm{Cu} / \mathrm{CNTs}$ catalyst and (b) CNTs sample.

\section{Catalytic performance evaluation}

The catalytic performance of the $\mathrm{CuCo} / \mathrm{CNTs}$ series of catalysts was studied and compared. The data is presented in Table 1 . As observed, the $15 \mathrm{Cu} / \mathrm{CNTs}$ catalyst exhibited low activity and presented considerably low CO conversion and STY. Furthermore, methanol is the major product across alcohols formation. Conversely, the $12.5 \mathrm{Cu} 2.5 \mathrm{Co} / \mathrm{CNTs}$ catalyst exhibited considerably higher catalytic performance. The $\mathrm{CO}$ conversion and total alcohol STY increased by one order of magnitude relative to that of the $15 \mathrm{Cu} / \mathrm{CNTs}$ sample. This result indicates that the addition of cobalt, even at low loading levels, has great influence on the properties of copper, and that there are synergistic effects between them. Additionally, the alcohol distribution results indicate that the reaction over $\mathrm{CuCo} / \mathrm{CNTs}$ tends to favor the formation of $\mathrm{C}_{2+}$ alcohols. Thus, both structural and electronic interactions may exist between copper and cobalt.

As observed, the 7.5Cu7.5Co/CNTs catalyst displayed high activity and the selectivity of ethanol reached up to ca. $30.1 \%$, with the selectivity for $\mathrm{C}_{2+}$ alcohols reaching ca. $57.7 \%$. The $10 \mathrm{Co} 5 \mathrm{Cu} / \mathrm{CNTs}$ catalyst displayed a larger STY (372.9 $\left.\mathrm{mg} \mathrm{g}_{\text {cat }}{ }^{-1} \mathrm{~h}^{-1}\right)$, together with a comparable higher alcohols distribution to that of the $10 \mathrm{Cu} 5 \mathrm{Co} / \mathrm{CNTs}$ sample. The $15 \mathrm{Co} / \mathrm{CNTs}$ catalyst had a considerably higher activity with a CO conversion of $48.8 \%$ and a corresponding total alcohol selectivity of $13.4 \%$. Further observations show that the selectivity for alcohols decreased as a function of increased cobalt loading in the catalysts. The excellent $\mathrm{C}_{2+}$ alcohols selectivity and yield are obtained over the catalyst with weight ratio of $\mathrm{Cu} / \mathrm{Co}=0.5-2$. Taking high $\mathrm{C}_{2+}$ alcohols selectivity, low $\mathrm{CO}_{2}$ selectivity and narrowed alcohols distribution into consideration, carbon nanotubesupported copper-cobalt catalyst turns to be better than $\mathrm{CuZnAl}{ }^{26}$ and $\mathrm{Cu}-\mathrm{Co} / \mathrm{Mn}_{2} \mathrm{O}_{3}-\mathrm{Al}_{2} \mathrm{O}_{3}{ }^{27}$ catalyst recently reported for higher alcohols synthesis.

It is also observed that $10 \mathrm{Cu} 5 \mathrm{Co}$-out-CNTs exhibited a remarkably lower catalytic performance than that of $10 \mathrm{Cu} 5 \mathrm{Co} / \mathrm{CNTs}$. The total alcohol STY decreased by $163.3 \mathrm{mg} \mathrm{g}_{\text {cat }}{ }^{-1} \mathrm{~h}^{-1}$, and furthermore, the total alcohols selectivity and the alcohol distribution results showed

Table 1. Catalytic performances of CuCo-based catalysts in $\mathrm{CO}$ hydrogenation

\begin{tabular}{|c|c|c|c|c|c|c|c|c|c|c|c|}
\hline \multirow{2}{*}{ Sample } & \multirow{2}{*}{$\begin{array}{c}\mathrm{CO} \\
\text { conversion / \% }\end{array}$} & \multirow{2}{*}{$\begin{array}{l}\text { Total alcohol } \\
\text { STY / } \\
\left(\mathrm{mg} \mathrm{g}_{\text {cat }}^{-1} \mathrm{~h}^{-1}\right)\end{array}$} & \multicolumn{4}{|c|}{ Carbon selectivity / (C mol\%) } & \multicolumn{5}{|c|}{ Alcohol distribution / (C mol\%) } \\
\hline & & & $\mathrm{CH}_{4}$ & $\mathrm{C}_{2}-\mathrm{C}_{4}$ & $\mathrm{ROH}$ & $\mathrm{CO}_{2}$ & $\mathrm{MeOH}$ & $\mathrm{EtOH}$ & $\mathrm{PrOH}$ & $\mathrm{BuOH}$ & $\mathrm{C}_{5} \mathrm{OH}$ \\
\hline $15 \mathrm{Co} / \mathrm{CNTs}$ & 48.8 & 256.5 & 68.5 & 9.1 & 13.4 & 9.0 & 59.2 & 25.1 & 10.1 & 5.2 & 0.4 \\
\hline $12.5 \mathrm{Co} 2.5 \mathrm{Cu} / \mathrm{CNTs}$ & 40.1 & 266.9 & 61.1 & 12.1 & 24.5 & 2.3 & 56.8 & 25.0 & 10.6 & 7.1 & 0.5 \\
\hline $10 \mathrm{Co} 5 \mathrm{Cu} / \mathrm{CNTs}$ & 38.9 & 372.9 & 48.5 & 14.0 & 35.8 & 1.7 & 52.7 & 26.5 & 12.5 & 7.3 & 1.1 \\
\hline 7.5Cu7.5Co/CNTs & 32.6 & 318.2 & 43.2 & 20.4 & 34.2 & 2.2 & 42.3 & 30.1 & 16.8 & 9.6 & 1.3 \\
\hline $10 \mathrm{Cu} 5 \mathrm{Co} / \mathrm{CNTs}$ & 28.9 & 292.3 & 44.9 & 17.6 & 36.3 & 1.2 & 50.0 & 28.0 & 13.0 & 7.8 & 1.2 \\
\hline $12.5 \mathrm{Cu} 2.5 \mathrm{Co} / \mathrm{CNTs}$ & 21.3 & 230.9 & 50.4 & 11.1 & 37.0 & 1.5 & 57.8 & 25.0 & 11.0 & 5.5 & 0.7 \\
\hline $15 \mathrm{Cu} / \mathrm{CNTs}$ & 3.5 & 21.4 & 30.3 & 29.7 & 27.1 & 12.9 & 85.1 & 9.1 & 4.0 & 1.8 & 0.1 \\
\hline 10Cu5Co-out-CNTs & 14.0 & 129.0 & 60.7 & 8.7 & 28.6 & 2.0 & 60.2 & 23.6 & 10.9 & 4.9 & 0.5 \\
\hline CNTs & 0 & 0 & - & - & - & - & - & - & - & - & - \\
\hline
\end{tabular}

Reaction conditions: slurry reactor, $300^{\circ} \mathrm{C}, 4.5 \mathrm{MPa}, 10000 \mathrm{~mL} \mathrm{gat}^{-1} \mathrm{~h}^{-1}, 2: 1 \mathrm{H}_{2}: \mathrm{CO}$ syngas ratio, TOS: $7 \mathrm{~h}$; $\mathrm{STY}$ : space-time yield; CNT: carbon nanotube. 
that particles on the outside were not as effective for HAS as particles inside the CNTs. In addition, the pure CNTs sample exhibited no activity for higher alcohols synthesis through $\mathrm{CO}$ hydrogenation.

\section{Correlation studies on the active sites and catalytic behavior}

\section{$\mathrm{H}_{2}$-TPR characterization}

The $\mathrm{H}_{2}$-TPR profiles of the fresh catalysts are presented in Figure 4. Specifically, the $15 \mathrm{Cu} / \mathrm{CNTs}$ sample exhibited a broad peak within the temperature range of 200 to $380^{\circ} \mathrm{C}$, which was attributed to the reduction of $\mathrm{Cu}_{2} \mathrm{O}$ and $\mathrm{CuO}$ based on the XRD results. The $15 \mathrm{Co} / \mathrm{CNTs}$ sample exhibited peaks centered at 292,395 and $520{ }^{\circ} \mathrm{C}$, which were primarily attributed to the reduction of $\mathrm{CoO}$ based on the XRD results. It was observed that the temperature of the first reduction peak decreased gradually as a function of increasing the $\mathrm{Cu}$ loading. Catalyst reduction is indicated to be influenced by the strong mutual effect of cobalt and copper, and the reduction of cobalt is considerably enhanced by the presence of copper, which results in an obvious enhancement of catalyst reducibility in our system. The similar conclusion was also proposed by other researchers. ${ }^{28,29}$ Hence, the first broad peak in the $\mathrm{CoCu} / \mathrm{CNTs}$ samples was attributed to the reduction of copper and cobaltous oxide. Additionally, a broad peak at ca. $480{ }^{\circ} \mathrm{C}$ was observed in all of these samples. To confirm the assignment of the broad peaks, TPR-mass spectrometry analysis was conducted and the results are shown in Supplementary Information section (Figure S1). It was found that a degree of cobaltous oxide was reduced at the higher temperatures, the addition of metals and metal oxides accelerated the decomposition of the nanotubes and their reduction peaks overlapped with the decomposition peak of the CNTs.

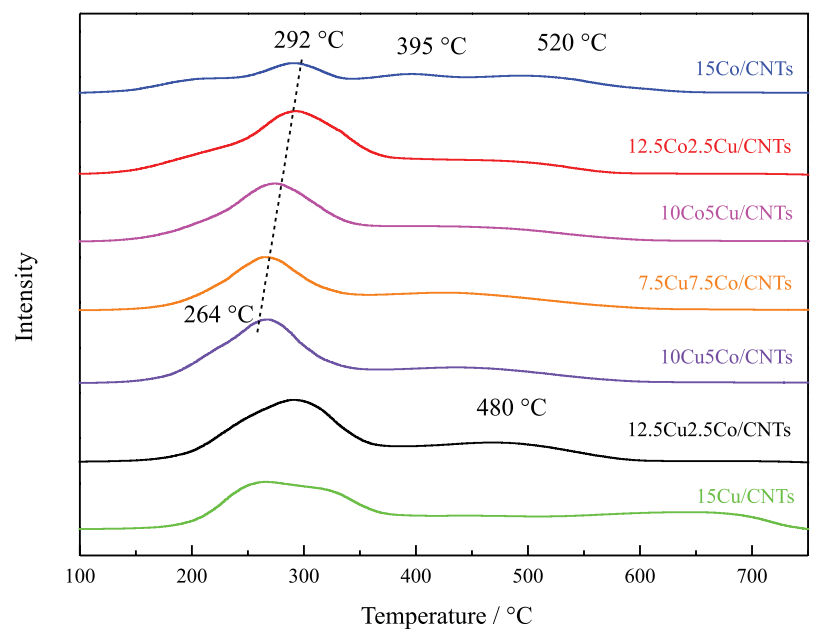

Figure 4. $\mathrm{H}_{2}$-TPR profiles of the fresh catalysts.

\section{XPS characterization}

XPS is typically employed to analyze the composition and oxidation states of catalyst surface species. Thus, in situ and ex situ XPS spectra of the $\mathrm{Cu} 2 \mathrm{p}, \mathrm{Co} 2 \mathrm{p}, \mathrm{C} 1 \mathrm{~s}$ and $\mathrm{O} 1 \mathrm{~s}$ core levels of the $10 \mathrm{Co} 5 \mathrm{Cu} / \mathrm{CNTs}$ and $15 \mathrm{Co} / \mathrm{CNTs}$ samples were recorded.

The Co 2p XPS spectra of the fresh and reduced $10 \mathrm{Co} 5 \mathrm{Cu} / \mathrm{CNTs}$ samples are shown in Figure 5a. The Co $2 \mathrm{p}_{3 / 2}$ main peak was observed at ca. $780.7 \mathrm{eV}$, along with a satellite peak at $786.7 \mathrm{eV}$. The peak with the lowest binding energy $(778.8 \mathrm{eV})$ is attributed to $\mathrm{Co}^{0}$, whereas the peak observed at the higher binding energy $(780.7 \mathrm{eV})$ is associated with $\mathrm{Co}^{2+}$ and the peak at $780.0 \mathrm{eV}$ attributed to the $\mathrm{Co}^{3+}$ state. ${ }^{30-32}$ To confirm the distribution of the Co species, the Co $2 \mathrm{p}$ XPS spectrum of the reduced $15 \mathrm{Co} / \mathrm{CNTs}$ sample was measured (Figure $5 \mathrm{c}$ ). The measured XPS surface layer revealed relative $\mathrm{Co} /\left(\mathrm{Co}^{0}+\mathrm{Co}^{2+}\right)$ ratios in the reduced $10 \mathrm{Co} 5 \mathrm{Cu} / \mathrm{CNTs}$ and $15 \mathrm{Co} / \mathrm{CNTs}$ catalysts of 2.92 and $3.61 \%$, respectively. Based on the experimental results, the $\mathrm{Co}^{2+}$ site is thought to be beneficial for high alcohol selectivity, associatively adsorption of $\mathrm{CO}$ on $\mathrm{Co}^{2+}$ site and coupling of $\mathrm{CO}$ and $\mathrm{CH}_{x}$ to form oxygenates. Similar results and discussion were also proposed by Wang et al. $^{33}$

As shown in Figure $5 b$, the $\mathrm{Cu} 2 \mathrm{p}_{3 / 2}$ spectrum of the fresh sample is characterized by a main peak at $932.69 \mathrm{eV}$ with a satellite peak appearing at a higher binding energy, indicating the presence of surface $\mathrm{Cu}^{2+} \cdot{ }^{34}$ Conversely, the $\mathrm{Cu} 2 \mathrm{p}_{3 / 2}$ spectrum of the reduced sample was characterized by symmetrical major peaks and the absence of satellite structures. As XPS and XAES data show, for the fresh sample, $\mathrm{E}_{\mathrm{b}}\left(\mathrm{Cu} 2 \mathrm{p}_{3 / 2}\right)$ is located at $932.69 \mathrm{eV}$ with an $\mathrm{E}_{\mathrm{k}}\left(\mathrm{CuL}_{3} \mathrm{VV}\right)$ value of $916.38 \mathrm{eV}$, giving an Auger parameter $\alpha^{\prime}(\mathrm{Cu})$, of $1849.07 \mathrm{eV}$, which is associated with $\mathrm{Cu}^{+}$. However, for the reduced sample, $\mathrm{E}_{\mathrm{b}}\left(\mathrm{Cu} 2 \mathrm{p}_{3 / 2}\right)$ and $\mathrm{E}_{\mathrm{k}}\left(\mathrm{CuL}_{3} \mathrm{VV}\right)$ values are 932.89 and $918.02 \mathrm{eV}$, respectively, giving an $\alpha^{\prime}(\mathrm{Cu})$ of $1850.91 \mathrm{eV}$, which is associated with $\mathrm{Cu}^{0} .{ }^{35}$ Therefore, it could be deduced that only metallic copper is present on the surface of the catalysts after in situ reduction.

Compositional analysis to obtain $\mathrm{Cu}$ and $\mathrm{Co}$ content of the bulk $10 \mathrm{Co} 5 \mathrm{Cu} / \mathrm{CNTs}, 7.5 \mathrm{Cu} 7.5 \mathrm{Co} / \mathrm{CNTs}$ and $10 \mathrm{Cu} 5 \mathrm{Co} / \mathrm{CNTs}$ samples is measured using inductively coupled plasma-atomic emission spectroscopy (ICP-AES) and data is presented in Supplementary Information section (Table S1). Actual metal content reveals incorporation in ratios consistent with theoretical loading values.

Combined with the characterization analysis and experimental results, two mechanistic pathways are assumed for the $\mathrm{CoCu}$-based catalysts in relation to the oxygenation of the generated carbon chain to form 

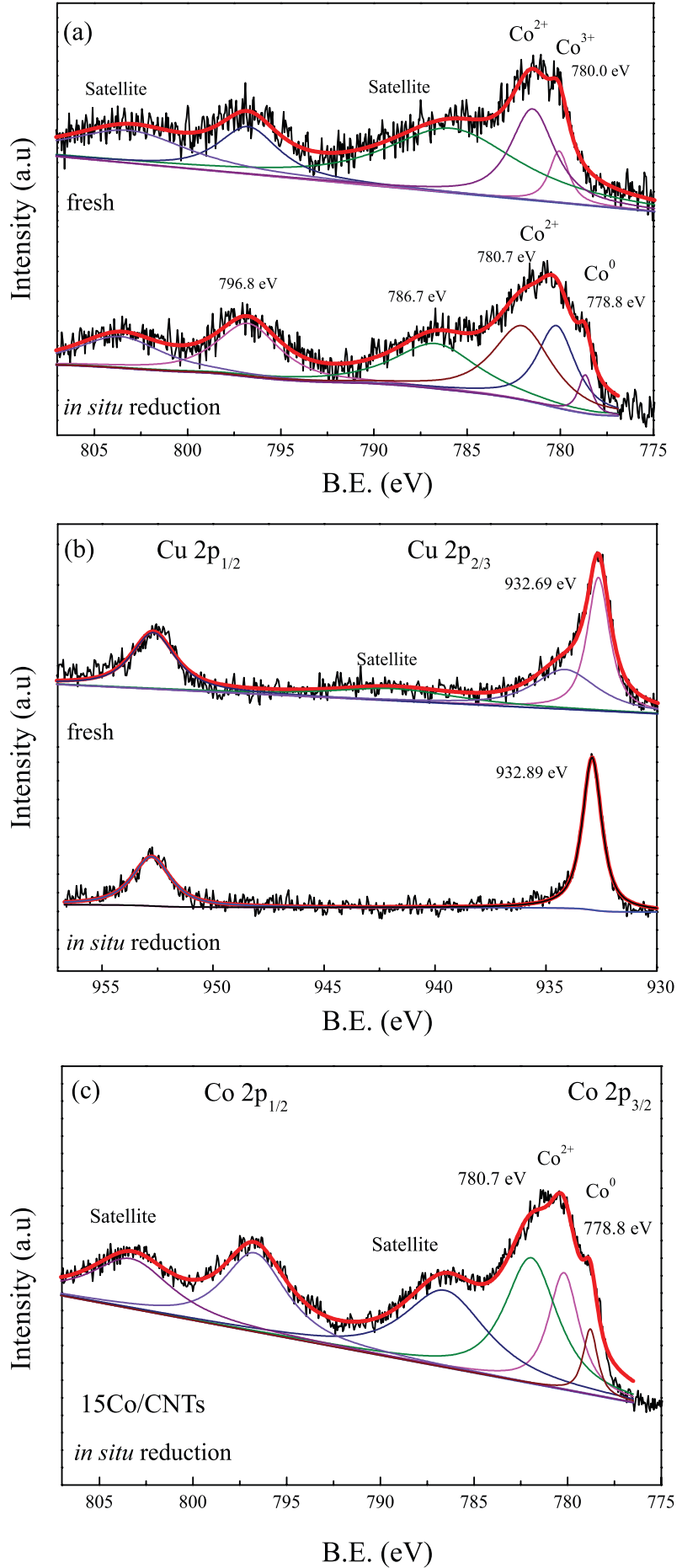

Figure 5. (a), (c) Co 2p and (b) Cu 2p XPS spectra of the fresh and reduced catalysts (in situ reduction was conducted in $\mathrm{H}_{2}$ at $673 \mathrm{~K}$ for $1 \mathrm{~h}$ ).

alcohols. The first route is a $\mathrm{Cu}^{0}-\mathrm{Co}^{0}$ center, with $\mathrm{Co}^{0}$ acting as an active site for $\mathrm{CO}$ dissociation, $\mathrm{C}-\mathrm{C}$ chain growth, and hydrogenation to produce ${ }^{\circ} \mathrm{C}_{\mathrm{n}} \mathrm{H}_{\mathrm{x}}$ groups, whereas $\mathrm{Cu}^{0}$ is the major site for methanol synthesis and is involved in the $\mathrm{CO}$ associative adsorption to form $\mathrm{CO}^{*}$. The $\mathrm{CO}^{\circ}$ moiety moves to the ${ }^{\circ} \mathrm{C}_{\mathrm{n}} \mathrm{H}_{\mathrm{x}}$ group (or vice versa) and is inserted via surface migration over a short distance between the $\mathrm{Cu}^{0}$ and $\mathrm{Co}^{0}$ sites for subsequent hydrogenation to produce higher carbon number alcohols. These alcohols synthesis mechanism has been termed as a $\mathrm{CO}$ insertion mechanism. ${ }^{36}$ The second dual active site for alcohol synthesis is via the $\mathrm{Co}^{0}-\mathrm{Co}^{2+}$ center, the surface reactions on these sites are similar to those on the $\mathrm{Cu}^{0}-\mathrm{Co}^{0}$ center. On the $\mathrm{Co}^{0}-\mathrm{Co}^{2+}$ dual sites, metallic cobalt is the active site for $\mathrm{CO}$ dissociation and chain propagation, while $\mathrm{Co}^{2+}$ is the active site for $\mathrm{CO}$ associative adsorption and $\mathrm{CO}$ insertion, therefore $\mathrm{Co}^{2+}$ sites favor high oxygenate yields. A similar route for chain growth termination to produce alcohols was also proposed by Baker et al. ${ }^{37}$ The metallic oxide Co pair $\left(\mathrm{Co}^{0}-\mathrm{Co}^{2+}\right)$ could explain why the $15 \mathrm{Co} / \mathrm{CNTs}$ sample also produces higher carbon number alcohols during the reaction; as shown in Table 1, the selectivity for total alcohol reaches up to $13.4 \%$. The proposed mechanism is illustrated in Scheme 1.

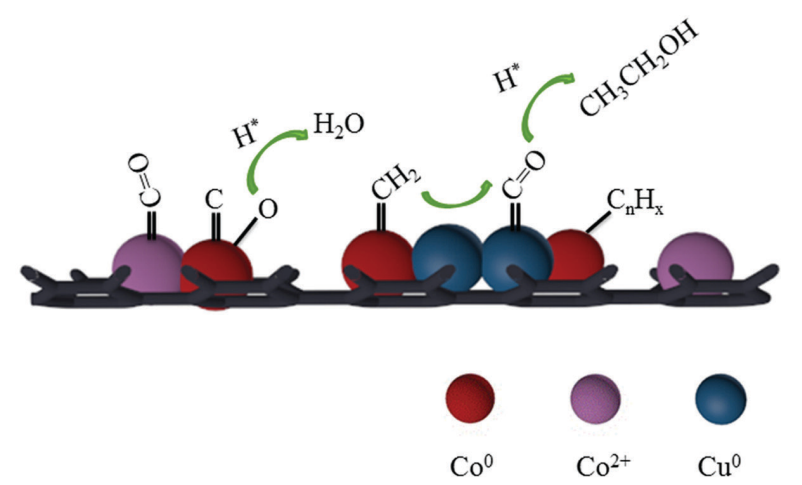

Scheme 1. Reaction model for the formation of higher alcohols over the $\mathrm{CuCo} / \mathrm{CNTs}$ catalyst.

The Anderson-Schulz-Flory (ASF) plots (logarithm of mole fraction $v s$. carbon number) for the distribution of alcohols obtained over four catalysts are shown in Figure 6. The carbon number distributions of alcohols obtained over the $15 \mathrm{Co} / \mathrm{CNTs}, 10 \mathrm{Co} 5 \mathrm{Cu} / \mathrm{CNTs}$ and $10 \mathrm{Cu} 5 \mathrm{Co} / \mathrm{CNTs}$ catalysts display excellent ASF plots. Partial deviation from the ASF distribution was observed for the 7.5Cu7.5Co/CNTs catalyst. The appropriate $\mathrm{Cu} / \mathrm{Co}$ ratio enhances the synergistic effect of the active species and improves $\mathrm{C}_{2+}$ alcohol selectivity.

\section{Conclusions}

We have demonstrated that the bimetallic catalyst with a $\mathrm{Cu} / \mathrm{Co}$ ratio from 0.5 to 2 favors higher carbon number alcohols formation during $\mathrm{CO}$ hydrogenation. The 7.5Cu7.5Co/CNTs catalyst exhibited a relatively high selectivity for the formation of ethanol $(30.1 \%)$ and $\mathrm{C}_{2+}$ alcohols $(57.7 \%)$ with a narrow range distribution, and 

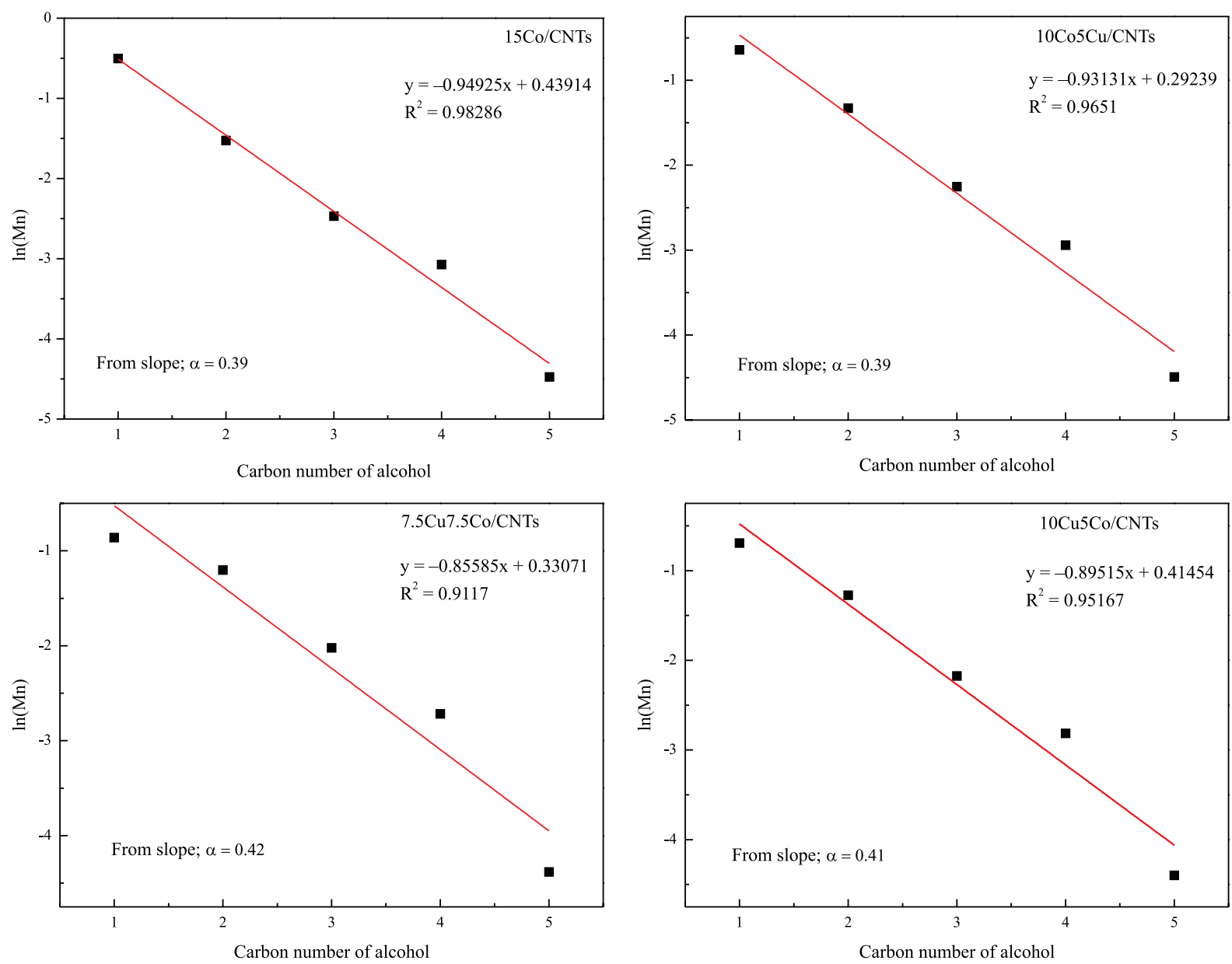

Figure 6. ASF plots for the distribution of alcohols obtained over the investigated catalysts.

the $10 \mathrm{Co} 5 \mathrm{Cu} / \mathrm{CNTs}$ catalyst displayed a high alcohol STY (372.9 $\left.\mathrm{mg} \mathrm{g}_{\text {cat }}{ }^{-1} \mathrm{~h}^{-1}\right)$.

The superior confinement effect allows intimate contact between the copper-cobalt active species in the nanotubes, which improves their geometric interactions and synergistic effect. The synergistic effect between copper and cobalt is crucial for optimal product distribution. Metallic copper alone shows negligible catalytic activity for $\mathrm{CO}$ hydrogenation, however, in the presence of $\mathrm{Cu}^{0}-\mathrm{Co}^{0}$ dual catalytic sites, $\mathrm{Cu}$ is effective, as the sites for the oxygenation of the generated carbon chains form alcohols, in addition to enhancing cobalt reduction. Furthermore, the $\mathrm{Co}^{0}-\mathrm{Co}^{2+}$ center is also beneficial to $\mathrm{HAS}$, the $\mathrm{Co}^{2+}$ site terminating the carbon chain growth to produce alcohols and favor alcohols yields. The ratio of $\mathrm{Cu} / \mathrm{Co}$ considerably influences metal particle properties and it likely plays an important role in determining the selectivity towards higher alcohols.

\section{Supplementary Information}

Supplementary data $\left(\mathrm{H}_{2}\right.$-TPR-MS, HRTEM and ICP results) are available free of charge at http://jbcs.sbq.org.br as PDF file.

\section{Acknowledgments}

This work was supported by the National Natural Science Foundation of China (grant No. 21573269), the Natural Science Foundation of the Jiangsu Higher Education Institutions of China (grants No. 17KJB150038 and 17KJB530010), the Research Project of Xuzhou Institute of Technology, China (grant No. XKY2016114), and Natural Science Foundation of Jiangsu Province, China (grants No. BK20171168 and BK20171169).

\section{References}

1. Luk, H. T.; Mondelli, C.; Ferré, D. C.; Pérez-Ramírez, J.; Chem. Soc. Rev. 2017, 46, 1358.

2. Gangwal, V.; Gangwal, S. K.; Energy Fuels 2008, 22, 814.

3. Wang, P.; Chen, S. Y.; Bai, Y. X.; Gao, X. F.; Sun, K.; Han, Y. Z.; Tan, Y. S.; Fuel 2017, 195, 69.

4. Gupta, M.; Smith, M. L.; Spivey, J. J.; ACS Catal. 2011, 1, 641. 
5. Wang, J. J.; Chernavskii, P. A.; Khodakov, A. Y.; Wang, Y.; J. Catal. 2012, 286, 51.

6. Fang, K. G.; Li, D. B.; Lin, M. G.; Xiang, M. L.; Wei, W.; Sun, Y. H.; Catal. Today 2009, 147, 133.

7. Medford, A. J.; Lausche, A. C.; Temel, B.; Schjodt, N. C.; Norskov, J. K.; Top. Catal. 2014, 57, 135.

8. Prieto, G.; Beijer S.; Smith, M. L.; Au, Y.; Wang, Z.; Angew. Chem., Int. Ed. 2014, 53, 6397.

9. Xiaoding, X.; Doesburg, E. B. M.; Scholten, J. J. F.; Catal. Today 1987, 2, 125.

10. Smith, K. J.; Anderson, R. B.; J. Catal. 1984, 85, 428.

11. Xiao, K.; Bao, Z. H.; Fang, K. G.; Lin, M. G.; Sun, Y. H.; Chin. J. Catal. 2013, 34, 116.

12. Subramanian, N. D.; Balaji, G.; Kumar, C.; Spivey, J. J.; Catal. Today 2009, 147, 100.

13. Khodakov, A. Y.; Griboval-Constant, A.; Bechara, R.; Zholobenko, V. L.; J. Catal. 2002, 206, 230.

14. Borg, Ø.; Eri, S.; Blekkan, E. A.; Storsæter, S.; Wigum, H.; Rytter, E.; J. Catal. 2007, 248, 89.

15. Khodakov, A. Y.; Bechara, R.; Griboval-Constant, A.; Appl. Catal., A 2003, 254, 273.

16. Karaca, H.; Safonova, O. V.; Chambrey, S.; Fongarland, P.; Roussel, P.; J. Catal. 2011, 277, 14.

17. Karaca, H.; Hong, J.; Fongarland, P.; Roussel, P.; Lacroix, M.; Chem. Commun. 2010, 46, 788.

18. den Otter, J. H.; Nijveld, S. R.; de Jong, K. P.; ACS Catal. 2016 , 6,1616 .

19. Deng, D.; Yu, L.; Chen, X.; Wang, G.; Jin, L.; Pan, X.; Angew. Chem., Int. Ed. 2013, 52, 371.

20. Chen, W.; Fan, Z.; Pan, X.; Bao, X.; J. Am. Chem. Soc. 2008, $130,9414$.

21. Chen, W.; Pan, X. L.; Willinger, M. G.; Su, D. S.; Bao, X. H.; J. Am. Chem. Soc. 2006, 128, 3136.

22. Pan, X.; Fan, Z.; Chen, W.; Ding, Y.; Luo, H.; Bao, X.; Nat. Mater. 2007, 6, 507.
23. Guan, J.; Pan, X. L.; Liu, X.; Bao, X. H.; J. Phys. Chem. C 2009, 113, 21687.

24. Guo, S.; Pan, X.; Gao, H.; Yang, Z.; Zhao, J.; Bao, X. H.; Chem. - Eur. J. 2010, 16, 5379.

25. Su, J.; Zhang, Z.; Fu, D.; Jiang, Z.; Xu, J.; Han, Y. F.; J. Catal. 2016, 336, 94.

26. Liu, Y.; Deng, X.; Han, P.; Huang, W.; Fuel Process. Technol. 2017, 167, 575 .

27. Zhao, L.; Li, W.; Zhou, J.; Mu, X.; Fang, K.; Int. J. Hydrogen Energy 2017, 421, 7414

28. Wang, J. J.; Chernavskii, P. A.; Khodakov, A.Y.; Wang, Y.; J. Catal. 2012, 286, 51.

29. Fierro, G.; Jacono, M. L.; Inversi, M.; Dragone, R.; Porta, P.; Top. Catal. 2000, 10, 39.

30. Reinikainen, M.; Niemelä, M. K.; Kakuta, N.; Suhonen, S.; Appl. Catal., A 1998, 174, 61.

31. Guczi, L.; Bazin, D.; Kovács, I.; Borkó, L.; Schay, Z.; Lynch, J.; Top. Catal. 2002, 20, 129.

32. Ernst, B.; Bensaddik, A.; Hilaire, L.; Chaumette, P.; Kiennemann, A.; Catal. Today 1998, 39, 329.

33. Wang, Z.; Kumar, N.; Spivey, J. J.; J. Catal. 2016, 339, 1.

34. Wang, J.; Chernavskii, P. A.; Wang, Y.; Khodakov, A. Y.; Fuel 2013, 103, 1111 .

35. Wang, P.; Huang, W.; Zhang, G.; Gao, Z.; Tang, Y.; Sun, K.; J. Ind. Eng. Chem. 2015, 26, 243.

36. Fang, K.; Li, D.; Lin, M.; Xiang, M.; Wei, W.; Sun, Y.; Catal. Today 2009, 147, 133.

37. Baker, J. E.; Burch, R.; Hibble, S. J.; Loader, P. K.; Appl. Catal. 1990, 65, 281.
Submitted: October 3, 2017

Published online: December 20, 2017 